\title{
REUTILIZAÇÃO DE RESÍDUOS DE CURTUME NA FABRICAÇÃO DE BLOCOS DE CONCRETO PARA PAVIMENTAÇÃO: AVALIAÇÃO DAS CARACTERÍSTICAS DO RESÍDUO
}

\author{
D. A. NARDINO ${ }^{1}$, V. B. PAIVA², F. NUNES ${ }^{2}$, J. G. SGORLON², M. C. S. GOMES ${ }^{1}$, M. L. \\ MENEZES $^{2}$ \\ ${ }^{1}$ Universidade Tecnológica Federal do Paraná, Curso Superior em Tecnologia em Processos \\ Químicos \\ ${ }^{2}$ Universidade Tecnológica Federal do Paraná, Coordenação do curso de Engenharia Química \\ E-mail para contato: dani-nardino@hotmail.com ;
}

RESUMO - A indústria de fabricação de couros está em constante crescimento trazendo consigo uma grande carga de resíduos. Um dos resíduos sólidos mais gerados nesse tipo de indústria é o chamado "pó de rebaixadeira". Este resíduo é gerado na etapa de acabamento do couro, onde o mesmo é raspado até atingir a espessura desejada pelo consumidor. Estas aparas são geradas em grandes quantidades por dia, possuem grande concentração de metais pesados em sua composição (principalmente $\mathrm{Cr}$ ), possuem baixo peso específico, são de difícil compactação e geralmente são destinadas a aterros industriais. $\mathrm{O}$ presente trabalho tem como objetivo a avaliação das características física, química e microestrutural do "pó de rebaixadeira" visando sua possível reutilização/tratamento na fabricação de blocos de concreto. Para a realização do trabalho, o resíduo sólido foi disponibilizado por um curtume localizado na cidade de Apucarana/PR, sendo o mesmo proveniente do curtimento das peles com cromo. O resíduo foi caracterizado por meio de análises de umidade, sólidos totais, matéria orgânica total, resíduo mineral total, carbono orgânico, lixiviação, solubilização e microscopia eletrônica de varredura (MEV). Os resultados obtidos permitiram verificar que, segundo a norma ABNT NBR 10004 (2004), os resíduos de aparas de couro ou "pó de rebaixadeira" é classificado como resíduo sólido Classe I - Perigoso, devido a sua elevada concentração de cromo, altamente tóxico. Além disso, o resíduo também apresentou altas concentrações de sódio $(\mathrm{Na})$, (utilizado na conservação do couro) no extrato solubilizado. Em contrapartida, as demais características apresentadas pelo rejeito, mostrou que o "pó de rebaixadeira", é um ótimo candidato para reutilização/tratamento utilizando-se a técnica de estabilização/solidificação em matrizes de cimento.

\section{INTRODUÇÃO}

A indústria de couros no Brasil tem mostrado um constante crescimento em sua produção. No ano de 2014, o valor alcançado pelas exportações de couros e peles chegou a 
US\$ 958,6 milhões, o que representa um crescimento de 25,5\% em relação ao mesmo período de 2013 (ABQTIC, 2014).

$O$ frequente aumento na produção de couros acaba por trazer uma grande preocupação para a indústria curtumeira, pois um de seus principais problemas é a disposição de resíduos ricos principalmente em sais de cromo, tais resíduos são gerados na etapa de curtimento do couro.

O curtimento com sais de cromo é o mais utilizado devido às suas vantagens como menor tempo, qualidade de estabilidade, maior resistência a água, proporciona maior elasticidade ao couro e é de fácil tingimento. No curtimento, o $\mathrm{Cr}$ (III) liga-se à proteína na pele do animal para formar o couro. Como consequência da emissão industrial, este elemento é um poluente aquático comum, especialmente de águas subterrâneas sob áreas com indústria de produção de metais. É também o segundo contaminante inorgânico mais abundante de águas subterrâneas sob locais de disposição de resíduos perigosos (BAIRD, 2011).

Uma das possíveis técnicas para a reutilização de efluentes e resíduos sólidos, tanto da indústria curtumeira quanto de outras indústrias correlatas é a técnica de solidificação/estabilização (s/e). O processo de s/e consiste em encapsular resíduos perigosos dentro de uma matriz sólida de grande integridade estrutural, além de estabilizar os resíduos perigosos e transformá-los em materiais menos poluentes. Trata-se de uma tecnologia que vem sendo utilizada como alternativa aos processos tradicionais de tratamento de resíduos e, principalmente, como um meio de facilitar o manuseio, o transporte e o armazenamento. Consiste, basicamente, em estabilizar, química e/ou fisicamente os resíduos sólidos, por meio de adição de aglomerantes ou da inserção em invólucros eficientes (PABLOS, 2008). Essa técnica pode ser implantada, por exemplo, na reutilização de resíduos sólidos, sem destinação adequada, na fabricação de produtos para construção civil.

Com isso, o presente trabalho tem como objetivo a caracterização físico-química e microestrutural do resíduo de uma das etapas do curtimento, o rebaixamento, com o intuito do conhecimento de suas principais propriedades, visando seu posterior tratamento/reutilização na confecção de peças de concreto.

\section{MATERIAIS E METODOS}

A amostra do resíduo, pó de rebaixadeira, foi coletada em um curtume localizado na cidade de Apucarana - Paraná. O resíduo foi armazenado em sacos plásticos em temperatura ambiente para posterior caracterização.

A análise de umidade e sólidos totais fizeram parte da caracterização física do resíduo, a caracterização química deu-se por meio das análises de pH, lixiviação, solubilização, matéria orgânica total, resíduo mineral total e carbono orgânico. A microscopia eletrônica de varredura fez parte da análise microestrutural do resíduo. A tabela 1 apresenta sucintamente as metodologias/equipamentos utilizados.

Tabela 1 - Análises e suas respectivas metodologias

\begin{tabular}{cc}
\hline Análise & Metodologia \\
Umidade & Kiehl (1985) \\
Sólidos totais & Kiehl (1985) \\
\hline
\end{tabular}




\section{$\mathrm{pH}$}

Matéria orgânica total

Resíduo mineral total

Carbono orgânico

Lixiviação

Solubilização

Microscopia eletrônica de varredura (MEV)
NBR10005 (2004)

Kiehl (1985)

Kiehl (1985)

Kiehl (1985)

NBR10005 (2004)/Espectrômetro de absorção atômica

NBR10006 (2004)/ Espectrômetro de absorção atômica e cromatógrafo de íons

Microscópio eletrônico de varredura de elétrons Philips FEI Quanta 200

\section{RESULTADOS E DISCUSSÃO}

A tabela 2 apresenta os resultados da caracterização físico-química do resíduo de curtume.

Tabela 2 - Características físicas e químicas do resíduo

\begin{tabular}{c|c|c|c|c|c}
\hline Análise & Amostra 1 & Amostra 2 & Amostra 3 & Média & $\begin{array}{c}\text { Desvio } \\
\text { padrão }\end{array}$ \\
\hline $\mathrm{pH}$ & 4,00 & 4,00 & 4,00 & 4,00 & 0,0 \\
Sólidos Totais (g/g) & 0,45 & 0,45 & 0,46 & 0,45 & 0,01 \\
Umidade (\%) & 55,00 & 54,50 & 54,30 & 54,60 & 0,29 \\
Matéria Orgânica Total (\%) & 84,40 & 83,40 & 84,60 & 84,10 & 0,53 \\
Resíduo Mineral Total (\%) & 15,60 & 16,60 & 15,40 & 15,90 & 0,53 \\
Carbono Orgânico (\%) & 46,89 & 46,33 & 47,00 & 46,74 & 0,29 \\
\hline
\end{tabular}

De acordo com os resultados obtidos, o resíduo apresentou um valor de $\mathrm{pH}$ ácido, em torno de 4. Essa acidez provavelmente é proveniente do tipo de curtimento. O curtimento do couro se dá, na maioria das vezes, em pH ácido, entre 3,5 e 3,8. Segundo Sundar et al., (2002), para que o cromo consiga penetrar na pele, o $\mathrm{pH}$ tem que estar abaixo de 3,0 , com isso é utilizado um pré-tratamento das peles com ácido sulfúrico e cloreto de sódio, para obter um $\mathrm{pH}$ de equilíbrio.

A amostra analisada apresentou um alto valor de umidade, aproximadamente 54,60\%, valor esse muito próximo aos valores de umidade para raspas de couro encontrado por Ribeiro et al., (2011). Esse resultado pode estará relacionado a etapa de coleta do resíduo, pois o mesmo foi coletado durante o processamento, ou seja, o couro que passou pelo rebaixamento ainda não estava totalmente seco gerando um resíduo bem úmido.

Em relação à matéria orgânica total, a mesma apresentou um valor médio de $84,10 \%$, destes, a fração de origem carbonácea é de cerca de $46,74 \%$. Em contra partida, o resíduo mineral total, que representa indiretamente o material inorgânico presente na amostra, atingiu 
um valor médio de $15,90 \%$. Tais resultados já eram esperados, visto que o resíduo tem origem animal.

A tabela 3 e a tabela 4 apresentam respectivamente, os valores obtidos para o extrato de lixiviado e extrato solubilizado do resíduo do processo de curtimento de peles, bem como as concentrações limites de cada contaminante estipulada pela norma ABNT NBR 10004 (2004) que determina a classificação dos resíduos de acordo com sua periculosidade.

Tabela 3 - Concentração de contaminantes presentes no extrato lixiviado do resíduo

\begin{tabular}{ccc}
\hline Contaminante & $\begin{array}{c}\text { Limite NBR } \\
10004 / 2004 \\
\left(\mathrm{mg} \mathrm{L}^{-1}\right)\end{array}$ & $\begin{array}{c}\text { Resíduo curtume } \\
\left(\mathrm{mg} \mathrm{L}^{-1}\right)\end{array}$ \\
\hline$B a$ & 70,00 & n.d \\
$C d$ & 0,50 & 0,01 \\
$P b$ & 1,00 & 0,24 \\
$C r$ & 5,00 & 127,88 \\
$A g$ & 5,00 & n.d \\
Fluoreto $\left(F^{-}\right)$ & 150 & n.d \\
\hline
\end{tabular}

n.d: não detectado pelo instrumento de análise

Tabela 4 - Concentração de contaminantes presentes no extrato solubilizado do resíduo

\begin{tabular}{cccccc}
\hline Contaminante & $\begin{array}{c}\text { Limite NBR } \\
10004 / 2004 \\
\left(\mathrm{mg} \mathrm{L}^{-1}\right)\end{array}$ & $\begin{array}{c}\text { Resíduo } \\
\text { curtume } \\
\left(\mathrm{mg} \mathrm{L}^{-1}\right)\end{array}$ & Contaminante & $\begin{array}{c}\text { Limite NBR } \\
10004 / 2004 \\
\left(\mathrm{mg} \mathrm{L}^{-1}\right)\end{array}$ & $\begin{array}{c}\text { Resíduo } \\
\text { curtume } \\
\left(\mathrm{mg} \mathrm{L}^{-1}\right)\end{array}$ \\
\hline $\mathrm{Al}$ & 0,20 & $\mathrm{n} . \mathrm{d}$ & $\mathrm{Mn}$ & 0,10 & 0,14 \\
$\mathrm{Ba}$ & 0,70 & $\mathrm{n} . \mathrm{d}$ & $\mathrm{Ag}$ & 0,05 & n.d \\
$\mathrm{Cd}$ & 0,005 & 0,02 & $\mathrm{Na}$ & 200 & 2597,14 \\
$\mathrm{~Pb}$ & 0,01 & 0,38 & Cloreto $\left(\mathrm{Cl}^{-}\right)$ & 250 & $\mathrm{n} . \mathrm{d}$ \\
$\mathrm{Cu}$ & 2,00 & 0,01 & Fluoreto $\left(\mathrm{F}^{-}\right)$ & 1,50 & n.d \\
$\mathrm{Cr}$ & 0,05 & 309,43 & Nitrato $\left(\mathrm{NO}^{3-}\right)$ & 10,00 & n.d \\
$\mathrm{Fe}$ & 0,30 & 3,31 & Sulfato $\left(\mathrm{SO}_{4}^{2-}\right)$ & 250 & n.d \\
\hline
\end{tabular}

n.d: não detectado pelo instrumento de análise

Por meio dos resultados apresentados na tabela 3, foi possível verificar que a concentração do metal cromo $(\mathrm{Cr})$ presente no extrato lixiviado do resíduo apresentou concentração superior ao estipulado pela norma NBR 10004 (2004). Com isso, o resíduo de curtume pode ser classificado como resíduo sólido Classe I - Perigoso. Segundo a norma supracitada, um resíduo perigoso pode apresentar riscos à saúde pública (mortalidade e incidência de doenças) e ao meio ambiente, quando for gerenciado de forma inadequada. A origem do alto valor do cromo nos resíduos da indústria de couros se dá pelo processo de curtimento, que utiliza como base o cromo trivalente $\left(\mathrm{Cr}^{+3}\right)$. As concentrações dos demais contaminantes ( $\mathrm{Ba}, \mathrm{Cd}, \mathrm{Pb}, \mathrm{Ag}$ e fluoreto) mantiveram-se dentro dos limites.

A tabela 4 apresenta os valores de concentração de contaminantes presentes no solubilizado do resíduo. Observa-se que os metais $\mathrm{Cd}, \mathrm{Pb}, \mathrm{Cr}, \mathrm{Fe}, \mathrm{Mn}$ e $\mathrm{Na}$ ultrapassaram os valores limites de concentração mantidos pela norma NBR 10004 (2004), porém, houve destaque novamente para a concentração de $\mathrm{Cr}$ e de $\mathrm{Na}$ que apresentaram, respectivamente, valores de seis mil vezes e trezes vezes maiores do que os limites da legislação. Assim como o cromo $(\mathrm{Cr})$, o sódio $(\mathrm{Na})$ também é utilizado durante o processo de curtimento das peles na 
indústria do couro, tal elemento é utilizado após a remoção da pele, para que não haja o apodrecimento precoce. Daí justifica-se a alta concentração desse metal presente no resíduo.

A figura 1 apresenta as micrografias referentes as análises de microscopia eletrônica de varredura (MEV). A técnica MEV permite conhecer as estruturas das amostras e suas interações.

Figura 1 - Microscopia eletrônica de varredura de amostras de resíduo de curtume: (a) ampliação 3000 vezes e (b) ampliação 1200 vezes.
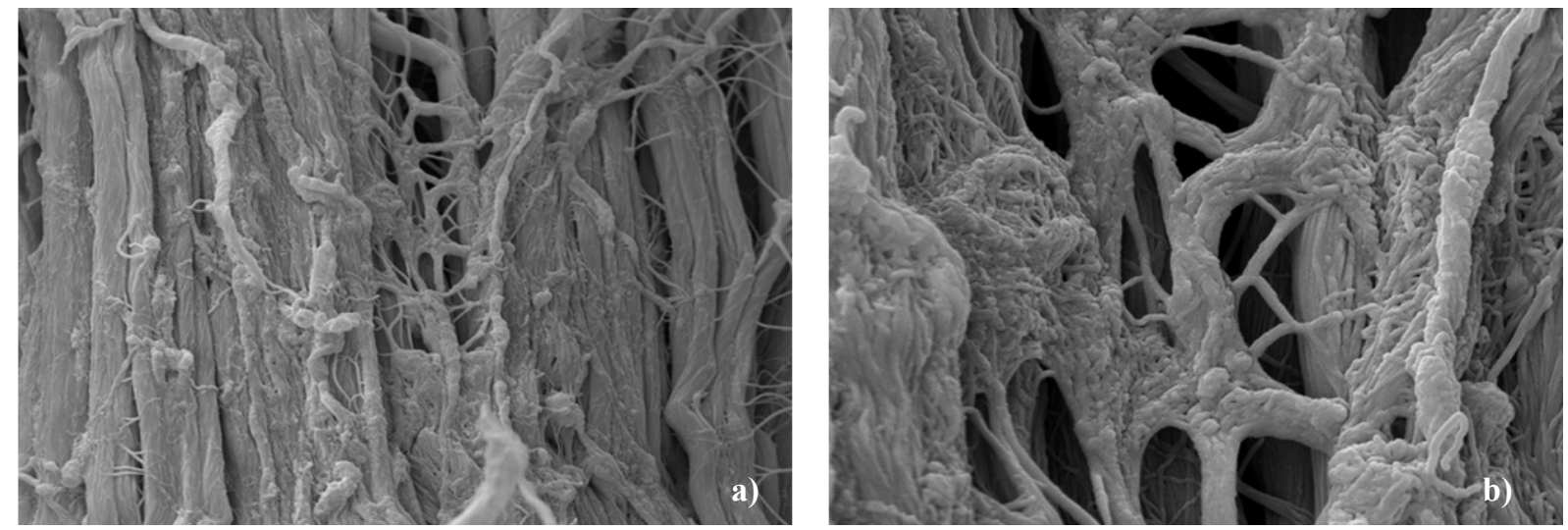

O intuito dessa análise foi conhecer a estrutura do resíduo e prever como será sua interação com o concreto, cuja pretensão será estabilizar metais pesados, principalmente o cromo, inibindo assim sua lixiviação/solubilização para o ambiente.

Por meio das micrografias pode-se observar as fibras que compõe o couro, bem como os poros ou vazios presentes no resíduo. Tal estrutura também foi observada por Ribeiro et al., (2011) em seu trabalho sobre adição de serragem de couro em concretos. A microestrutura apresentada pelo resíduo pode favorecer o contato íntimo ou interação do mesmo com a matriz estabilizante (concreto), possibilitando a eficácia do processo de estabilização/solidificação dos contaminantes.

\section{CONCLUSÃO}

Por meio das análises realizadas foi possível conhecer tanto a estrutura do pó de rebaixadeira como também suas características químicas e físicas, com o intuito de sua reutilização/tratamento em concretos.

$\mathrm{O}$ resíduo apresentou $\mathrm{pH}$ ácido, umidade em torno de $55 \%$, grande quantidade de matéria orgânica, principalmente carbonácea, e uma razoável concentração de sólidos. Além disso, as raspas de couro foram classificadas como resíduo sólido Classe I - perigoso, o que reforça ainda mais a necessidade de uma reutilização e tratamento adequado para o rejeito.

A análise de microscopia eletrônica de varredura mostrou que devido ao entrelaçamento das fibra do couro e os poros apresentados em sua matriz, poderá haver um favorecimento da interação do resíduo com o concreto, proporcionando assim, uma melhor eficiência para o processo de encapsulamento dos metais.

Por fim, conclui-se que o resíduo sólido "pó de rebaixadeira" ou raspas de couro wet blue, proveniente de uma das etapas da transformação de peles em couro nos curtumes, é um 
ótimo candidato para reutilização/tratamento utilizando-se a técnica de estabilização/solidificação com matrizes de cimento.

\section{REFERÊNCIAS}

ABNT. ASSOCIAÇÃO BRASILEIRA DE NORMAS TÉCNICAS. NBR 10004. Resíduos Sólidos - Classificação. Rio de Janeiro, 2004.

. NBR 10005. Procedimento para Obtenção de Extrato Lixiviado de Resíduos Sólidos. Rio de Janeiro, 2004.

. NBR 10006. Procedimento para Obtenção de Extrato Solubilizado de Resíduos Sólidos. Rio de Janeiro, 2004.

. NBR 10007. Amostragem de Resíduos Sólidos. Rio de Janeiro, 2004.

ABQTIC. Exportações de couro e os números de abril. Disponível em < http://www.abqtic.com.br/site/content/noticias/index.php?id=968\#9889873841311783>. Acesso em: 15 de março de 2014.

ABREU, Mírian A. de. Reciclagem do resíduo de cromo da indústria do curtume como pigmentos cerâmicos. 2006. 169 f. Tese (Doutorado em Engenharia) - Escola Politécnica da Universidade de São Paulo, São Paulo, 2006.

BAIRD, Colin; CANN, Michael. Química Ambiental. Tradução: Marco Tadeu Grassi, et al; $4^{a}$ ed. Porto Alegre. Bookman, 2011.

KIEHL, E. J. Fertilizantes Orgânicos. São Paulo: Editora Agronômica - CERES, 1985.

PABLOS, J. M. Estudo para a reutilização do resíduo sólido constituído pelas areias de fundição aglomeradas com argila, através da técnica de solidificação/estabilização em matrizes de cimento Portland, para aplicação no setor da construção civil. 2008. 146p. Tese - (Doutorado em Arquitetura e Urbanismo), Universidade de São Paulo, São Carlos, 2008.

RIBEIRO, D. V.; YUAN, S. Y.; MORELLI, M. R. Efeito da adição de serragem de couro tratada quimicamente nas propriedades do cimento Portland. Quím. Nova, v. 34, n. 6, p. 979-983, 2011.

SUNDAR, V. J.; RAO, J. R, MURALIDHARAN, C. Cleaner Chrome Tanning - Emerging Options. Journal of Cleaner Production 10, p. 69 - 74, Adyar, Chennai, India, 2002. 